\title{
Energy Audit: A Case Study in FTK Building Universiti Malaysia Pahang
}

\author{
"Roziah Zailan and Mohd Tarmizy Che Kar \\ Faculty of Engineering Technology, Universiti Malaysia Pahang, Lebuhraya Tun Razak, 26300, \\ Gambang Kuantan Pahang \\ "Email: roziahz@ump.edu.my
}

\begin{abstract}
The energy audit program was carried out for Faculty of Engineering Technology (FTK), University Malaysia Pahang by internal energy audit team. This paper presented annual energy consumption trend for FTK building, measurement finding for room data survey (air conditioning temperature and humidity comfort performance \& $\mathrm{CO}_{2}$ level for air quality) and lighting, Building Energy Index (BEI) value and appropriate recommendation in regards of energy saving practice and technological solution. According to those analysis, value for Building Energy Index (BEI) in FTK building is $98.035 \mathrm{kWh} / \mathrm{m}^{2} /$ year, Air Conditioning Energy Index (ACEI) is $73.254 \mathrm{kWh} / \mathrm{m}^{2} /$ year while for Lighting Energy Index (LEI) is $11.402 \mathrm{kWh} / \mathrm{m}^{2} /$ year. Total energy consumption estimated for 2017 is 31, $7951.375 \mathrm{kWh}$ per year. The implementation of the proposed energy conservation measures were expected to give positive results where the total cost saving per year is estimated about RM 48,551.20. Finally, it was recommended to implement three major energy conservation measures (ECMs) in specific: implementation of Sustainable energy management system (SEMS), maintenance of air conditioning system and retrofitting of LED lighting. As a result, FTK is targeted to achieve $30 \%$ annual energy saving about from the total energy consumption.
\end{abstract}

Indexed Terms- Energy Audit Program; Annual energy consumption; Room Data Survey; Building Energy Index; Energy Saving.

\section{INTRODUCTION}

Energy auditing is known as the verification, monitoring and analysis of use of energy followed by submission of technical report containing recommendation for improving energy efficiency with cost benefit analysis and an action plan to reduce energy consumption. Basically, an energy audit is conducted by an energy auditor and involves a detailed building inspection and analysis of how efficiently energy is being used [1].

There are various strategies potential to be adopted to promote green aspects in building sector includes; showcase energy efficient buildings, public awareness campaigns, incentives on less energy consumption, use of efficient appliances thus targeting general public and private sector with pulling strategy [2].

Paper from Sukri et al (2012) [3] has presented the energy management program conducted at the Faculty of Electrical Engineering, Universiti Teknologi Malaysia where the result has shown a reduction of EEI among the building in the faculty between $5 \%$ to $14 \%$. For this reason, this energy audit finding stood out as a stepping stone prior to the implementation of SEMS in the FTK.

FTK building is designated for Faculty of Engineering Technology, Universiti Malaysia Pahang. This three floor building sized $2,923.7 \mathrm{~m}^{2}$, operated within 8 hours daily and accommodated with around hundred lecturers and administration staffs of the faculty.

With full cooperation from the management of FTK, the energy audit program was completed in April 2017 with initial walk through audit to collect building information as well as energy 
consumption data. It followed by standard audit by conducted lighting measurement and room data survey (temperature, humidity and $\mathrm{CO}_{2}$ ). Electricity analysis also has been done to estimate electricity cost incurred for FTK building.

In fact, this project was conducted to achieve few energy performance goals in FTK building. It was conducted specifically to determine critical factors that lead to high energy consumption in FTK building, identify major opportunities to reduce the amount of energy consumed without negatively affecting occupant comfort and operations as well as to set a benchmark (Reference point) for managing energy in the organization. All in all, the energy audit act as basis for planning effective use of energy throughout FTK.

Towards the end, three ECMs including low cost and medium cost have been proposed; ECM1-implementation of SEMS, ECM2-maintenance of air conditioning system and ECM3retrofitting of LED lighting. As a result, FTK is targeted to achieve $30 \%$ annual energy saving from current total energy consumption.

\section{METHODOLOGY}

During the walk-through audit, all those data have been collected; layout plan, electricity bill and technical information for electrical equipment (air conditioning system \& lighting system). In addition, electrical consumption analysis was executed based on electricity bill.

Next, followed by standard audit where two types of on-site measurement were performed; room data survey (air conditioning temperature and humidity comfort performance \& $\mathrm{CO}_{2}$ level for air quality) and lighting measurement in the administrative office, meeting room, student lounge, FTK lounge and lecturer rooms. Energy audit equipment used to measure all those parameters were lux meter, temperature humidity meter and indoor air quality analyser.

Post audit analysis were followed with the determination of Energy Consumption Index including Building Energy Index (BEI), Air Conditioning Index (ACEI) and Lighting Energy Index (LEI). These indexes are representing actual energy consumption of the building by on-site measurement [3]. Finally, energy and cost saving were calculated to recommend preventive action of excessive energy consumption or ECMs.

The audited areas of building and operation data are summarized as in Table 1.

Table 1: Building and Operation Data

\begin{tabular}{|c|c|}
\hline Area & No \\
\hline FTK Lounge area & 1 \\
\hline Student lounge & 1 \\
\hline Discussion room & 1 \\
\hline Pantry & 6 \\
\hline Meeting room & 1 \\
\hline Office area & 4 \\
\hline Toilet & 24 \\
\hline Lecturer rooms & 32 \\
\hline Employees & 100 \\
\hline Working hours & $176 \mathrm{~h}$ \\
\hline
\end{tabular}

\section{ELECTRICAL COMPONENTS IN FTK BUILDING}

\subsection{Air Conditioning System}


Air conditioning system in FTK building is fitted with split unit air conditioning and ceiling mounted air conditioning. Administration office and every lecturer rooms are installed with one split unit air conditioning with two main components: an outdoor compressor/condenser, and an indoor airhandling unit. A conduit, which houses the power cable, refrigerant tubing, suction tubing, and a condensate drain, links the outdoor and indoor units. Individual wall mounted air conditioners giving cooling to each lecturer rooms individually. Only meeting room is using ceiling cassette 4 way airconditioning are the same system such as split unit air conditioning system just the differences is the size, and cooling capacity.

\subsection{Lighting System}

The whole building are installed with fluorescent lamp as the main lighting system while only several spaces are using LED lamp like meeting room and student lounge. Fluorescent lamp fitting is equipped with the light reflector and fin in square shape. The reason of conventional lighting choice is due to the age of building and it is now possible to retrofit into LED technology for energy saving preference.

\section{ENERGY AUDITING FINDING}

\subsection{Load Apportioning}

Figure 1 shows load apportioning for overall FTK building. As shown in the illustration, air conditioning consumes the highest amount of electrical energy which is around $63.2 \%$. Followed by office equipment (computer/laptop, fax machine, printers, photocopy machine etc.) about $16.1 \%$. Meanwhile, lighting system contributes about $9.8 \%$ and remaining $10.8 \%$ of electricity consumption is coming from other appliances such as water dispenser, electric kettle and microwave. The energy consumption after translated into costing resulted total monthly energy costs about RM 13,486.44 as shown in Table 2.

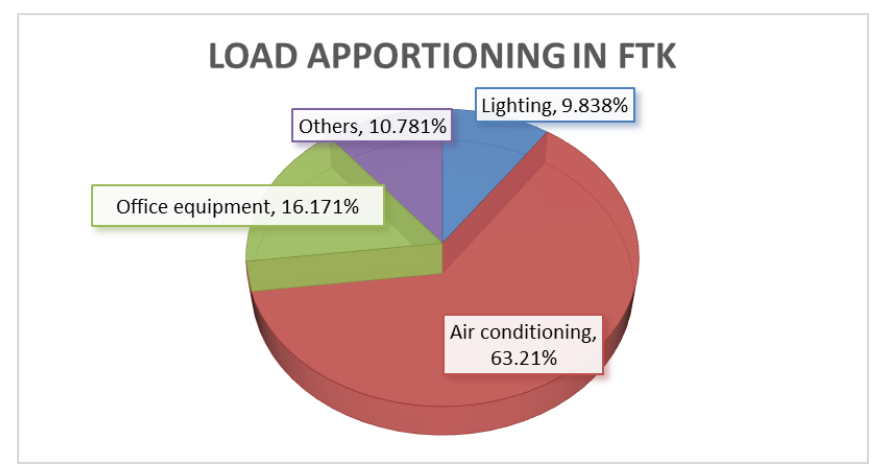

Figure 1: Load Apportioning in FTK Building

Table 2: Monthly Calculated Energy Consumption and Cost in FTK Building

\begin{tabular}{lccc}
\hline Application & $\begin{array}{c}\text { Energy Consumption } \\
(\mathrm{kWh})\end{array}$ & $\begin{array}{c}\text { Energy Consumption } \\
\text { Cost }(\mathrm{RM})\end{array}$ & $\begin{array}{c}\text { Percentage of Energy } \\
\text { Consumption Cost }(\%)\end{array}$ \\
\hline Lighting & 2606.77 & $1,326.85$ & 9.8 \\
\hline
\end{tabular}




\begin{tabular}{lccc}
\hline Air conditioning & $16,748.16$ & $8,524.81$ & 63.2 \\
Office equipment (Computer/ & $4,284.53$ & $2,180.83$ & 16.2 \\
laptop) & & & 10.8 \\
Others & $2,856.49$ & $1,453.95$ & 100 \\
Total & $26,495.95$ & $13,486.44$ & \\
\hline
\end{tabular}

\subsection{Energy Wasting Practice Observation}

Office works environment usually can be associated with usage of computers/laptops and numbers of electrical devices. Excessive usage of devices leads to energy wastage [4]. Here are some practices or major causes that might be causing energy wastage in FTK;

\subsubsection{Usage of air conditioning system}

The whole indoor spaces in FTK building are fully air conditioned. One unit of air conditioner requires the power input of about 1000 watt. There are total of 50 units of air conditioner used just for this building. Turned out about 50000 watt of power is required to cool the space just for one day. This consumes high amount of energy and increase the cost of electricity. More power required if staffs setting the temperature to the maximum coolness $\left(16^{\circ} \mathrm{C}\right)$.

\subsubsection{Computer / IT wastage}

The usage of computer or laptops and other office equipment are indisputable in the faculty. However, if those equipment are used improperly, it may causes energy wastage. Currently, energy saving practices among staffs already cultured by UMP where they are reminded to put office equipment in the sleep mode or switch off when not in use. Such awareness were disseminate through memo and stickers in the working spaces.

\subsubsection{Lighting system}

When it comes to lighting, many people make the mistake of using lights to affect the brightness of an entire room, which can contribute to high electric bills. However, lighting is efficient only when used directly to provide light to specific areas of work spaces [5]. Lighting system accounts for more than $10 \%$ of the energy consumption in this building. The building orientation is not capable to exploit natural day lighting, therefore artificial lighting is the main option instead. From the observation, lighting that are not in used sometimes are being switched on and lead to energy expenditure.

\subsection{Energy Management System}

Energy management system give emphasize towards the efficient and sustainable energy management model. The objective is to enable one organization to control and managing energy consumption in efficient ways. Besides that, it can also help to reduce energy cost and optimizing energy consumption efficiently [5]. Basically, basic energy awareness has been dispersed to the staff, however, such energy management system is not formally established yet in the FTK. Energy consumption trend in the faculty is considered inefficient due to some reasons:

a. No systematic energy management system that outlined the energy policy, objectives, action plan and comprehensive energy monitoring.

b. Lacking in the operation and maintenance of inefficient electricity components.

c. No previous energy audit program was executed, therefore nobody care about the importance of energy saving measures and finding of solution. 
The respected energy management matrix in Figure 2 described current status of energy management system in FTK building. Obviously, there is no explicit energy policy in this building, however there is only an unwritten set of guidelines. Besides that, there is no corporate commitment and formal involvement in energy management. For marketing part, informal contacts are used to promote energy efficiency. Only low cost measures were taken at this moment. Thus, in this paper, SEMS is proposed to improve current situation into specified target in the energy matrix.

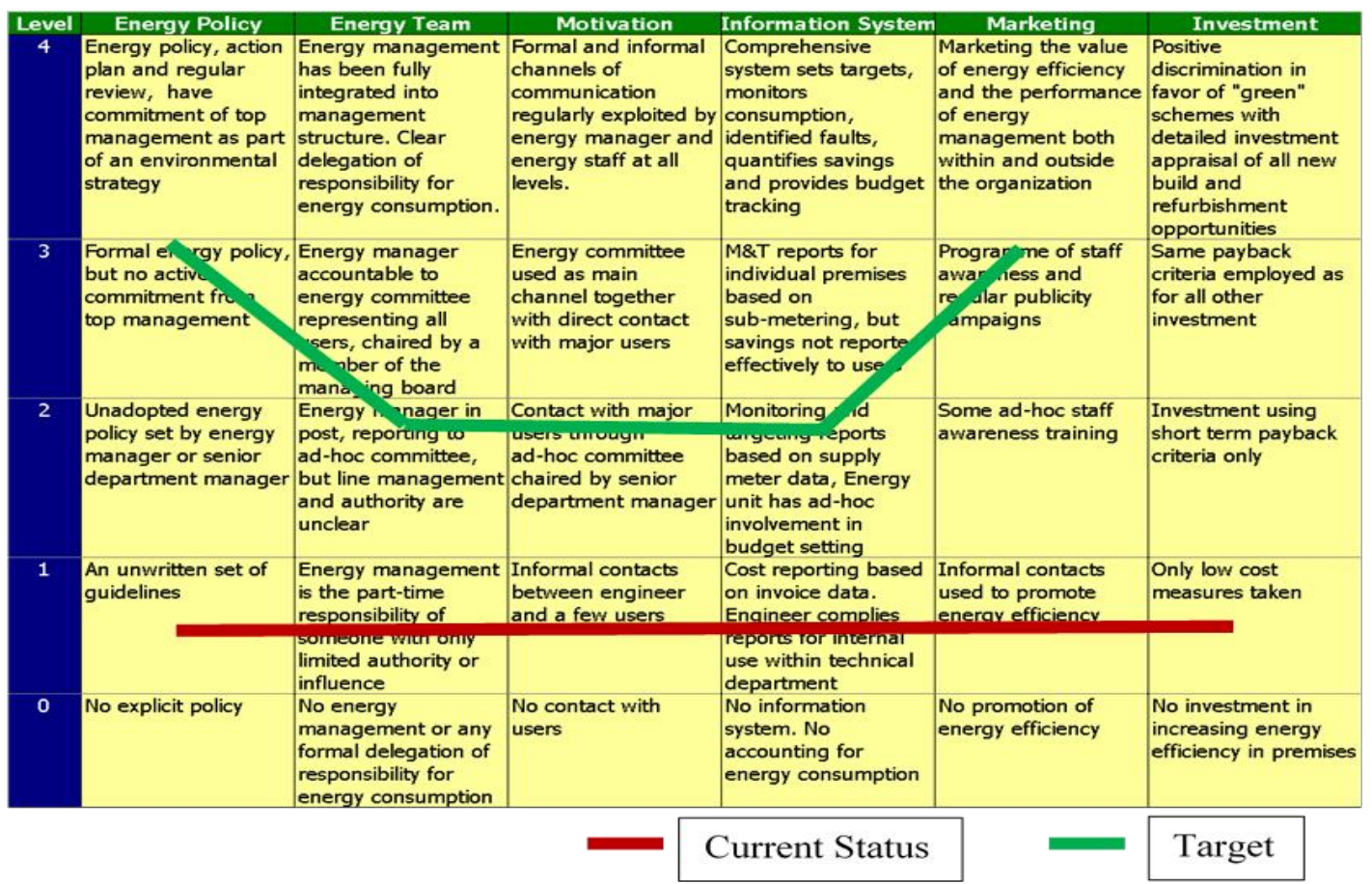

Figure 2: Energy Management Matrix for FTK

\subsection{Air Conditioning System Measurement Finding}

Normally air conditioning system consumes highest energy in any building. This same goes to FTK building, which consume approximately $63.2 \%$ of the total energy consumption. All indoor spaces in the building is air conditioned for at least 8 hours per day. Air conditioning temperature and humidity comfort performance data were collected at 5 locations. The measurement was done during normal office hours with occupancy in the respective area. According to Department of Standards Malaysia (2014) [6], the air conditioning temperature comfort performance is divided into 3 levels:

1. Conditioned space area that achieve the recommended level of comfort based on the reference MS 1525: 2014 which has a temperature range between $23^{\circ} \mathrm{C}-26^{\circ} \mathrm{C}$.

2. Conditioned space area where the temperature is less than the recommended level of comfort

$\left(<23^{\circ} \mathrm{C}\right)$

3. Conditioned space area where the temperature exceed the recommended level of comfort $\left(>26^{\circ} \mathrm{C}\right.$ )

Meanwhile, for relative humidity is: 
1. Conditioned space area that achieve the recommended level of comfort based on the reference MS 1525: 2014 which has relative humidity (RH) range between 50\%-70\%

2. Conditioned space area where the relative humidity (RH) is less than the recommended level of comfort or known as dry condition $(\leq 50 \%)$

3. Conditioned space area where the relative humidity $(\mathrm{RH})$ exceed the recommended level of comfort or known as humid condition ( $\geq 70 \%$ )

The finding shows $80 \%$ achieved the recommended level of comfort with temperature range between $23^{\circ} \mathrm{C}-26^{\circ} \mathrm{C}$. In the other hand, all areas achieve the recommended level of comfort which recorded relative humidity $(\mathrm{RH})$ range between $50 \%-70 \%$. Most of the working spaces were received adequate coolness however, it would be better to lifting temperature set point to $24^{\circ} \mathrm{C}$ as to reduce energy consumption in the production of chilled air.

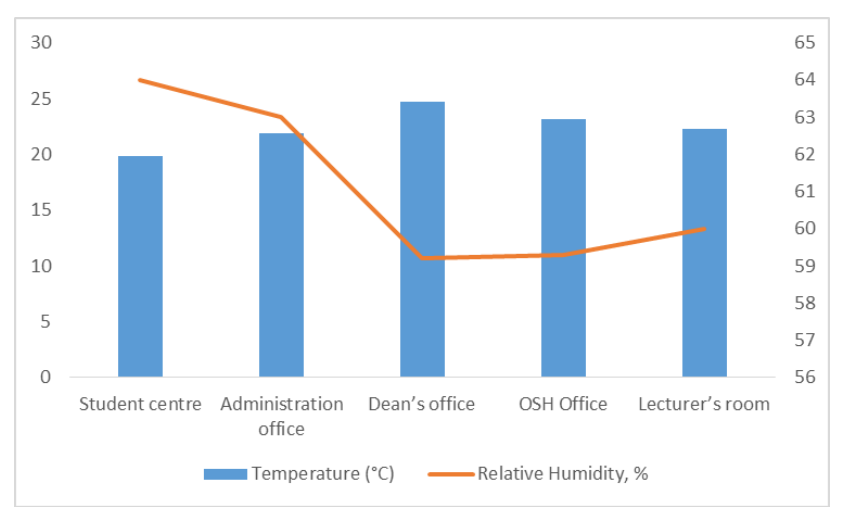

Figure 3: Temperature and Humidity Distribution in FTK Building

\subsection{Lighting System}

Illuminance is the total luminous flux incident on a surface, per unit area. It is a measure of how much the incident light illuminates the surface, wavelength-weighted by the luminosity function to correlate with human brightness perception. The unit used to measure illuminance is flux per unit area or lumen per square meter [5]. The illuminance in FTK Building was measured by using lux meter device to determine the lighting comfort performance. According to Musa et al. (2012) [7] and Department of Standard Malaysia (2014) [6], the lighting comfort performance is categorised into 3 levels:

1. Conditioned space area that achieve the recommended level of comfort which has a standard range between $300-500$ lux

2. Conditioned space area where the illuminance is less than the recommended level of comfort $(<300 \operatorname{lux})$

3. Conditioned space area where the illuminance exceed the recommended level of comfort (> $500 \operatorname{lux})$

Figure 4 showing that out of 7 measurement points, 43\% was acceptable (300-500), 43\% was overlit $(>500)$ and only $14 \%$ was underlit $(<300)$. Lighting is one of the most important parameter in achieving the good Indoor Environment Quality (IEQ). This situation will affect the quality of works and cause vision health problem if they receive insufficient lighting [7]. Apparently, lighting quality in FTK building is deliberated as good, however indicated overlit spaces may trigger energy wastage problem in the faculty. 


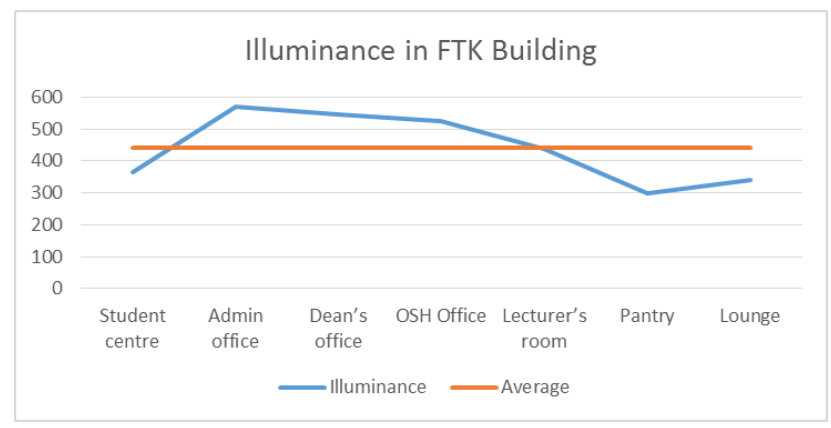

Figure 4: Illuminance in FTK Building

\subsection{Indoor Air Quality Level}

Indoor Air Quality (IAQ) refers to the air quality within and around buildings and structures, especially as it relates to the health and comfort of building occupants. Understanding and controlling common pollutants indoors can help reduce risk of indoor health concerns [8]. $\mathrm{CO}_{2}$ concentration in air were recorded in 5 locations and as in Figure 5.

The air quality performance is categorised into 3 levels (Department of Standard Malaysia, 2010):

1. Space area that achieve the recommended level of comfort based on the reference MS 1525: 2014 which has amount of carbon dioxide that range between 500-700ppm

2. Space area that has amount of carbon dioxide which is less than the recommended level of comfort $(<500 \mathrm{ppm})$

3. Space area that has amount of carbon dioxide which exceed the recommended level of comfort (> $700 \mathrm{ppm})$

It was recorded that $80 \%$ of the locations was considered normal with $\mathrm{CO}_{2}$ concentration $500-700 \mathrm{ppm}$ $\mathrm{CO}_{2}, 20 \%$ of spaces has less amount of $\mathrm{CO}_{2}(<500 \mathrm{ppm})$ and $20 \%$ exceeded the recommended level $(>700 \mathrm{ppm})$. Such condition does not pose serious sick building symptom due to poor indoor environment quality. High potential health threats like headache, fatigue, respiratory problems, and irritations or allergies of nose, eyes and throat may arise when the air consisting of pollutants such as biological contaminants, chemicals, particles and aerosols [9].

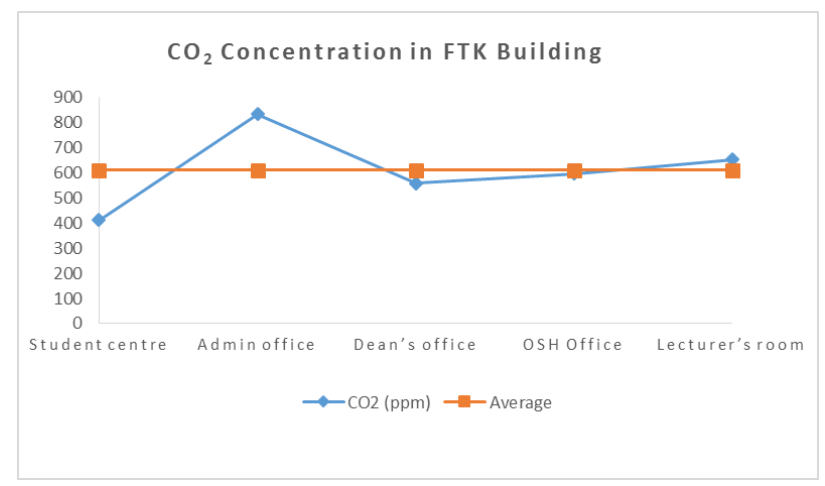

\subsection{Energy Building Index}

Figure 5: $\mathrm{CO}_{2}$ Concentration in FTK Building

Simply measuring the amount of energy used per a chosen time period does not take into account building size, configuration or type of use. When benchmarking a building, one of the key metrics is 
energy consumption index. Essentially, the use of an energy consumption index indicator, also known as Energy building Index (BEI) provides the means to equalize the way that energy used is compared between various types of buildings, and evaluate the means of reducing overall energy consumption [3]. Building energy index (BEI), Air-conditioning energy index (ACEI) and Lighting energy index (LEI) have been calculated in this study:

I. Air Conditioning Energy Index (ACEI)

Total gross floor area $=2,923.7 \mathrm{~m}^{2}$

Building Energy Index (BEI)

BEI = Total energy consumed in one year/Total gross floor area of the building

$=(26,495.948 \mathrm{kWh}) \times 12$ months $/\left(2,923.7 \mathrm{~m}^{2}\right)$

$=108.75 \mathrm{kWh} / \mathrm{m}^{2} /$ year

II. Air Conditioning Energy Index (ACEI)

ACEI = Total energy consumed of AC system in one year/ Total gross floor area $=(16,748.16 \mathrm{kWh}) \times 12$ months $\left(2,923.7 \mathrm{~m}^{2}\right)$

$=68.74 \mathrm{kWh} /$ year $/ \mathrm{m}^{2} /$ year

III. Lighting Energy Index (LEI)

LEI $=$ Total energy consumed of lighting system in one year / Total gross floor area $=(2,606.768 \mathrm{kWh}) \times 12$ months $\left(2,923.7 \mathrm{~m}^{2}\right)$

$=10.7 \mathrm{kWh} / \mathrm{m}^{2} /$ year

\subsection{Energy Conservation Measures Recommendation}

In regards to achieve energy saving goal in this building, three ECMs including low cost and medium cost were considered. It attenuated to air conditioning system, lighting system, and office equipment. All these components are the factors that contribute to increasing of energy consumption which can cause waste of energy usage is uncontrolled and monitored.

\section{ECM1-Sustainable Energy Management System (SEMS)}

Sustainable energy management system framework may be implemented to achieve energy saving in the faculty. Generally, there are various method to reduce energy utilisation like switching off the lights, air conditioning and other appliances when they are not in use. Resetting the air conditioning temperature to comfort level between $23^{\circ} \mathrm{C}$ to $26^{\circ} \mathrm{C}$ also very effective to save energy. Energy saving awareness program also are sought after among the organisation to support the successful of sustainable energy management system [5]. Energy saving was estimated about 5\% from SEMS where the complete breakdown of energy saving is shown as in Table 3.

Table 3: Summary of ECM1 - Sustainable Energy Management System

\begin{tabular}{lc}
\hline Item & Total \\
\hline Energy Consumption for One Year (kWh/year) & $317,951.40$ \\
Cost for One Year (RM/year) & $161,837.25$ \\
Energy Saving for One Year (kWh/year) & $15,897.57$ \\
Cost Saving for One Year (RM/year) & $8,091.86$ \\
$\mathrm{CO}_{2}$ Reduction for One Year & $6,044.62$ \\
(kg of $\mathrm{CO}_{2} /$ year) & \\
Total Investment (RM) & $20,000.00$ \\
Payback Periods & 2.47 years \\
\hline
\end{tabular}




\section{ECM 2- Air Conditioning system Maintenance}

Air conditioning system provide cooling for this building and also responsible for providing fresh outdoor air to dilute unnecessary contaminants such as odours from occupants and volatile organic compounds (VOC). A properly designed system will provide a comfortable indoor environment if it is properly maintained and managed [5]. Therefore, it is recommended to provide regular maintenance such as by changing air filter especially during high operation time. If the filter looks dirty after a month, it should be change. But if it might be difficult to change it in every 1 month, minimum 3 month maintenance can be accepted. A dirty filter will slow down air flow and increase the energy consumption thus wasting more energy. A clean filter will also prevent dust and dirt from building up in the system.

This also important to ensure a comfortable condition for occupant and at the same time reduce the energy wasted. By estimating 15\% energy saving from ECM2- maintenance of air conditioning system, the cost analysis breakdown of energy saving portrayed in Table 4.

Table 4: Summary of ECM2 - Air Conditioning system Maintenance

\begin{tabular}{ll}
\hline Item & Total \\
\hline Energy Consumption for One Year (kWh/year) & $317,951.40$ \\
Cost for One Year (RM/year) & $161,837.25$ \\
Energy Saving for One Year (kWh/year) & $47,692.70$ \\
Cost Saving for One Year (RM/year) & $24,275.60$ \\
$\mathrm{CO}_{2}$ Reduction for One Year (kg of CO $2 /$ year) & $35,626.45$ \\
Total Investment (RM) & $30,000.00$ \\
Payback Periods & 1.24 years \\
\hline
\end{tabular}

\section{ECM3- Retrofitting of LED lighting}

Lighting system is major component in FTK building where large opportunities of energy savings Lighting control is one of the easiest ways to make substantial energy savings for a relatively small investment and is one of the most common energy saving measures [7]. Therefore, in this study it is proposed to retrofit lighting by using light-emitting diode (LED) at the FTK building to save energy, especially when replacing incandescent fixtures or in colored lighting applications. LEDs also last longer than incandescent or fluorescent fixtures therefore reducing maintenance cost [5]. In this building, there are some LED lighting installed but there still a fluorescent light used that will effect energy consumption of the building. Therefore by fully installing LED light, it can reduce down the energy consumption. It was estimated about $10 \%$ saving from the retrofitting of LED lighting, therefore the breakdown of energy saving was estimated as in Table 5.

Table 5: Summary of ECM3- Retrofitting of LED lighting

\begin{tabular}{ll}
\hline Item & Total \\
\hline Energy Consumption for One Year (kWh/year) & $317,951.40$ \\
Cost for One Year (RM/year) & $161,837.25$ \\
Energy Saving for One Year (kWh/year) & $31,795.14$ \\
Cost Saving for One Year (RM/year) & $16,183.73$ \\
$\mathrm{CO}_{2}$ Reduction for One Year & 23,751 \\
(kg of $\mathrm{CO}_{2}$ /year) & \\
Total Investment (RM) & $30,500.00$ \\
Payback Periods & 0.96 year \\
\hline
\end{tabular}




\section{CONCLUSION}

In a nutshell, air conditioning system in FTK building consumes the highest energy, followed by lighting and office equipment usage. Throughout the energy audit program, it was recommended to implement three major energy conservation measures in specific: implementation of Sustainable Energy Management System, maintenance of air conditioning system and retrofitting of LED lighting. The cost summary is tabulated as in Table 6 as a whole. Those ECMs were targeted to achieve 30\% energy saving about out of total energy consumption.

Table 6: Summary of All Proposed ECM

\begin{tabular}{|c|c|c|c|c|c|}
\hline ECM & $\begin{array}{l}\text { Energy } \\
\text { saving }\end{array}$ & & Investment (RM) & $\begin{array}{l}\text { Pay Back } \\
\text { period (years) }\end{array}$ & $\begin{array}{l}\mathrm{CO}_{2} \text { reduction } \\
\left(\mathrm{kg} \text { of } \mathrm{CO}_{2} / \text { year }\right)\end{array}$ \\
\hline & $\mathrm{kWh}$ & $\mathrm{RM}$ & & & \\
\hline ECM1 & 15,897 & 8,091 & 20,000 & 2.5 & $6,044.62$ \\
\hline ECM2 & 47,692 & 24,275 & 30,000 & 1.2 & $35,626.45$ \\
\hline ECM3 & 31,795 & 16,183 & 30,500 & 1 & 23,751 \\
\hline Total & 95,385 & 48,551 & 80,500 & 4.7 & $65,422.07$ \\
\hline
\end{tabular}

\section{ACKNOWLEDGEMENTS}

The acknowledgement goes to Faculty of Engineering Technology, Universiti Malaysia Pahang for giving full support throughout the energy audit program.

\section{REFERENCES}

[1] Jamaludin, A. A., Mahmood, N. Z., \& Ilham, Z. (2017). Performance of electricity usage at residential college buildings in the University of Malaya campus. Energy for Sustainable Development, 40, 85-102. https://doi.org/10.1016/j.esd.2017.07.005

[2] Pervez H. S., N., Nor, M., Sahito, A. A., Nallagownden, P., Elamvazuthi, I., \& Shaikh, M. S. (2017). Building energy for sustainable development in Malaysia: A review. Renewable and Sustainable Energy Reviews, 75(May 2015), 1392-1403. https://doi.org/10.1016/j.rser.2016.11.128

[3] Sukri, A., Yusri, M., Abdullah, H., Rahman, H. A., Majid, M. S., \& Bandi, M. (2012). Energy Efficiency Measurements in a Malaysian Public University. 2012 IEEE International Conference on Power and Energy (PECon), 2-5 December 2012, (December), 2-5. https://doi.org/10.1109/PECon.2012.6450281

[4] Saidur, R. (2010). A review on electrical motors energy use and energy savings. Renewable and Sustainable Energy Reviews, 14(3), 877-898. https://doi.org/10.1016/j.rser.2009.10.018

[5] Thumann, A., \& Younger, W. (2008). Handbook of Energy Audits. $7^{\text {th }}$ Edition. The Fairmont Press, Inc.USA.

[6] Department of Standards Malaysia (2014). Malaysian Standard. MS 1525:2014. Energy efficiency and use of renewable energy for non-residential buildings - Code of practice (Second revision).

[7] Musa, A. R., Abdullah, N. A. G., Che-Ani, A. I., Tawil, N. M., \& Tahir, M. M. (2012). Indoor Environmental Quality for UKM Architecture Studio: An Analysis on Lighting Performance. Procedia - Social and Behavioral Sciences, 60(1994), 318-324. https://doi.org/10.1016/j.sbspro.2012.09.386 
[8] Vilčeková, S., Kapalo, P., Mečiarová, L', Burdová, E. K., \& Imreczeová, V. (2017). Investigation of Indoor Environment Quality in Classroom - Case Study. Procedia Engineering, 190, 496-503. https://doi.org/10.1016/j.proeng.2017.05.369

[9] Tiow C. Y. (2014). Indoor Environmental Quality (IEQ): A Case Study In Taylor's University, Malaysia. International Journal of Engineering and Applied Sciences, 5(7). 